\title{
Early childhood educators' experiences in their work environments: Shaping (im)possible ways of being an educator?
}

\author{
TAMARA CUMMING \\ Charles Sturt University (Australia)
}

\begin{abstract}
The purpose of this article is to explore the complex interrelations between educators' work environments and their experiences as an entryway for thinking differently about workforce stability and sustainability. Concepts of macro- and micropolitics (drawn from the work of Deleuze and Guattari) are used to explore one educator's experiences in her work environment through readings of visual, textual and affective data. These readings are then used as prompts for thinking differently about the complexity of educators' experiences in their work environments, and for generating other possibilities for supporting workforce stability and sustainability.
\end{abstract}

\section{Introduction}

The stability and sustainability of the early childhood workforce is critical to the achievement of policy goals in many national contexts - including the Australian context. Despite efforts to address early childhood workforce stability (i.e. the reduction of turnover and attrition of educators - Gable, Rothrauff, Thornburg \& Mauzy, 2007) and sustainability (i.e. maintaining numbers of educators, their wellbeing and capacity over the long term) these challenges appear entrenched. Research concerned with workforce challenges such as these has identified some of the complex aspects of work environments that have impacts for educators' experiences. For example, it appears that for some educators, experiences relating to cultures in work environments (The Social 
Research Centre, 2014), pay and conditions (Cassidy, Lower, Kintner-Duffy, Hegde, \& Shim, 2011), dominant discourses (Osgood, 2010) or disillusionment (Noble \& MacFarlane, 2005) may contribute to whether they stay or leave a work environment (turnover), or the sector altogether (attrition). However, in line with Sumsion's (2007, p. 318) contention that: "researchers... have been slow to address in theoretically or conceptually innovative ways the staffing challenges faced by the ECEC sector", few studies have focused upon ways that educators experience and negotiate aspects of contextual complexity. Might exploring these ideas help to generate new insights that could assist in better addressing challenges to workforce stability and sustainability?

As an entryway for thinking differently about these challenges, the purpose of this article is to draw on one beginning educator's (pseudonym 'Lara') experiences of negotiating the complexity of her work environment. To do this, concepts including macro- and micro-politics (based on Deleuze and Guattari's thinking) have been utilised to read relations between Lara's experiences and her work environment, and what these exchanges produce. The readings of (im)possible ways of being an educator produced through these exchanges are then used as prompts for thinking differently about workforce stability and sustainability.

The article begins with details of the Australian early childhood workforce context, then moves to a brief review of research concerned with educators' work environments - including organisational, relational and discursive elements. Next come details of key concepts put to work in the article, and of the research study from which data read in this article were generated. This is followed by an outline of the analytic strategies used to generate readings of Lara's experiences, then, the readings themselves. The article concludes with possibilities for ongoing thinking about workforce stability and sustainability, and suggestions for continued enquiry and action.

\section{The Australian early childhood workforce context}

Supporting workforce stability and sustainability is critical to the effectiveness of early childhood education policy across many national contexts (International Labour Organization [ILO], 2014). However, over a long period, efforts to improve early childhood workforce stability have had limited success (Organisation for Economic Cooperation and Development, 2012). In order to generate new possibilities, research and policy attention now appears to be shifting to a focus on improving the sustainability of the workforce (see for example, Sumsion, 2007; Standing Committee on Education and Early Childhood [SCSEEC], 2012). In the Australian context, this discourse of workforce sustainability underpins a range of workforce measures that are part of the large-scale reform of Australia's early childhood education sector. This reform agenda includes the development and implementation of a new quality assessment and ratings systems, national early childhood curriculum guidelines and a multi-faceted strategy for workforce development (Department of Education [DE], 2014). These initiatives are part of an extensive agenda that has nationalised the previously fragmented approaches of Australia's federal government and eight state and territory jurisdictions. 
As part of these initiatives, measures to increase educators ${ }^{1}$ qualifications and their professional status (SCSEEC, 2012) have been connected to the development of a "sustainable, highly qualified and professional workforce" (SCSEEC, 2012, p. 3). However (as discussed in detail elsewhere - (Cumming, Sumsion \& Wong, 2015) the narrow focus of these measures may mean they will have limited success. In addition, there are few signs that the current Australian Federal Government will fund additional targeted measures to support workforce retention (Productivity Commission, 2014). Yet, the critical role of the early childhood workforce in the success of the reform agenda remains - indicating the importance of generating ways of better supporting and sustaining it.

\section{Research review}

Research concerned with challenges to workforce stability and sustainability has identified a range of interrelated aspects of work environments that seem to have impacts on educators' experiences. In a study conducted in 13 classroom in the United States, for example, researchers noted that: "low salaries, lack of benefits, and difficult working conditions" (Cassidy, Lower, Kintner-Duffy, Hegde, \& Shim, 2011, p. 2) seemed to contribute to low morale, stress and a "compromised organizational climate" (p. 3). In addition, unsatisfactory relationships with colleagues, or feeling professionally isolated (Noble \& Macfarlane, 2005) seemed to contribute to turnover, particularly among university-qualified educators (Gable et al., 2007; Cassidy et al., 2011). Data from a recent early childhood workforce census in Australia have also indicated that factors such as culture and job stress may contribute to educators' decisions to change work environments, or to leave the field altogether (The Social Research Centre, 2014).

There also seem to be a number of organisational and relational aspects that play a role in supporting or undermining educators' "ability to apply their knowledge and skills" (Whitebook \& Ryan, 2011, p. 6) in their work environments. Among these aspects are: the amount of support (and the uniformity of support) among owners, managers and leaders for educators' professional development and paid planning time; opportunities for educators to make pedagogical decisions individually and collaboratively; and, action to support the financial, physical and mental well-being of educators (Sumsion, 2004; Whitebook \& Ryan, 2011).

Research has also identified a range of effects for educators relating to the "discursive landscape" of their work environments (Osgood, 2010). These 'landscapes' may be shaped by dominant discourses that (for example) circulate to make certain ways of practising in work environments acceptable or unacceptable. Sumsion (2001) and Hard (2006) for example, discuss ways that workplace violence (in the form of alienation, repression and neglect based on perceptions of difference) can affect educators' self-esteem, and their capacity to practice professionally. Similarly, in a South

${ }^{1}$ In Australia, all staff working directly with children are referred to as 'educators', regardless of their qualifications. 
Korean study conducted by Kim (2004), educators were ostracised by colleagues on the basis of their level of qualifications (that is, gained through vocational or university institutions). These experiences were reported to have contributed to some participants' decisions to leave the early childhood sector.

At the same time, there are also indications in research studies of aspects of work environments that support stability and sustainability. For example, one German study with over 460 respondents indicated that educators' job satisfaction was strongly associated with having a "sense of community and [the] quality of leadership" (Kusma, Groneberg, Nienhaus, \& Mache, 2012, p. 197). Another study, with seven educators in the Australian context, indicated that educators' resilience was supported by working in an environment consistent with their own philosophies and commitment to early childhood education (Sumsion, 2004).

The research reviewed here indicates some of the potentially generative connections between aspects of educators' work environments and experiences, and workforce sustainability. In order to expand on these possibilities, yet keeping in mind Sumsion's (2007) call for more innovative approaches, I take a post structural perspective drawing on the work of Deleuze and Guattari, to explore relations between educators and their work environments. In the next section of the article I outline the concepts I have put to work in readings of 'Lara's' experiences of her work environment.

\section{Concepts for rethinking}

\section{Macro- and micropolitics}

The concepts I have used to explore relations between educators and their work environments draw from the work of Deleuze and Guattari (1987). The first of these concepts is that of macro- and micropolitics. The concept of the macro and micro is often associated with sociological categories used to differentiate large-scale structures (such as governments) from individual agency (May, 2005). However, Deleuze and Guattari (1987, p. 231) contend that "there is no opposition between the central and the segmentary", writing instead about macro- and micropolitics as forces or flows, that act to regularise or stabilise (macro-political forces), or to disrupt and reorganise (micropolitical forces). Further, they contend that all societies and individuals have macro- and micropolitics that "coexist and cross over into each other" (Deleuze and Guattari, 1987, p. 235) in constant exchanges. Drawing on these understandings then, relations between work environments and educators might be conceptualised as exchanges of regularising and disrupting forces that work to produce change.

Other researchers using Deleuze and Guattari's concepts (including macro- and micropolitics) have indicated the possibilities that they have enabled for "previously unthought questions, practices, and knowledge" (Mazzei \& McCoy, 2010, p. 504). Olsson (2009) for example, used Deleuze and Guattari's concepts to re-energise possibilities for movement and experimentation in educators' practice. Pacini-Ketchabaw (2013) rethought the concept of 'transitions' in early childhood practice by using Deleuze and 
Guattari's concepts to explore spaces between-times. Using concepts of macro- and micropolitics to rethink relations between educators and work environments may then also generate new thinking and possibilities for thinking differently about workforce sustainability.

Being an educator

Another concept (drawing on the work of Deleuze and Guattari) that I use in this article is 'being' -particularly as part of the term 'ways of being an educator'. This term is used to convey a conceptualisation of being as a momentary part of a constant process of becoming. Becoming is understood here as a "threshold" space, a state of being inbetween where we have been, and where we may go (Jackson \& Mazzei, 2013, p. 264). According to these ways of thinking about being and becoming, subjects are not seen as constant identities, or as operating from particular positions, but: "assembled... in continuous and continuously transforming relation with the world" (Olsson, 2009, p. 45). These "processes of arranging, organising, and fitting together" (Livesey, 2010, p. 18) in which subjects are produced are what Deleuze and Guattari (1987) call assemblages. These are "complex constellations of objects, bodies, expressions, qualities, and territories, that come together for varying periods of time to ideally create new ways of functioning" (Livesey, 2010, p. 18). The ways macro- and micropolitical flows operate between these elements can change the capacity of the elements to act in enabling or constraining ways.

\section{Details of the research study}

The data I draw upon in this article were generated through a research study conducted in late 2012 and early 2013. The study explored educators' ways of negotiating complexity in early childhood practice in the Australian context. This question emerged from an interest in how educators might go about navigating the extensive changes affecting their sector. Ten participants took part, all women, and working in a variety of settings in the state of New South Wales (Australia's most populous state). Seven participants were employed in centre-based settings, three were (respectively): working in an individual child's home, in a mobile playgroup setting, or, studying to enter another part of the education sector.

For the purposes of the research study (from which data for this article were drawn), the research question was framed as being concerned with ways participants negotiated mixed messages (defined as contradictory ideas about ways of doing and being in early childhood settings). Enquiry around this question involved four phases. In phase one, an initial focus group discussion was conducted, centring upon participants' experiences of negotiating mixed messages in practice. In phase two, participants generated visual materials extending on ideas generated in the first focus group. In phase three, I held individual research conversations with each participant. Each conversation worked with the participant's visual materials, as well as ideas about negotiating mixed messages generated during the initial focus group. Phase four 
involved a follow-up focus group discussion. Each discussion expanded upon the data regarding ways of negotiating mixed messages that had been generated through the original focus group, visual materials and research conversations. I also shared with participants some of my early analysis of the data, and participants also used these readings as the basis for discussion (see Cumming \& Sumsion, 2014 for more detail).

Readings of visual, textual and affective data in this article centre around 'Lara' (a pseudonym) - an educator working in a long day care centre ${ }^{2}$ in Sydney, Australia. Lara had completed a teaching degree (qualifying her to work with children aged birth-12 years) in the year prior to the research study. In her first year of being an educator Lara had already progressed to become a room leader of the preschool age room, and deputy director of the 65 place centre ${ }^{i 3}$. Lara had entered her first teaching position with a sense of optimism and excitement, and a desire to make a difference. As the readings (below) of her experiences show however, her desired way of being an educator met with forces she had not anticipated, and she struggled to maintain a space for being different and effecting change.

\section{Analytic strategies}

To identify data fragments, and to read connections between Lara and her work environment, I used a process Deleuze described as "reading intensively" (1995, p. 8). In this type of reading: "something comes through or it doesn't. There's nothing to explain, nothing to understand, nothing to interpret. It's like plugging in to an electric circuit...' (Deleuze, 1995, p. 8). Reading intensively involves reading for affect - moments of intensity in which the capacity of a body (human or other-than-human) to act is changed. An example of affect in research data could be a research participant reporting ways that others' behaviours or choices make a range of other things more or less possible. It is this sense of a shift of possibilities in a text (of any form) that provides an affective alert when reading intensively (see Cumming, 2014 for more details).

Accordingly, the data I drew upon for the readings in this article came through moments of intensity as I read, and re-read the textual, affective, and visual data generated through my research project (moments of intensity are indicated for readers with bold type in quotes throughout the article). The shifts between possibilities and (seeming) impossibilities in Lara's accounts had particular resonance for my interest in ways educators negotiated complexity in early childhood practice. Hence this article

${ }^{2}$ Long day care centres are usually open between the hours of $7.30 \mathrm{am}-6 \mathrm{pm}$, for 50 weeks of the year. Children attending may be aged 6 weeks to 5 years. These centres provide a preschool program for children in the year (sometimes two years) prior to attending school.

${ }^{3}$ This experience is common to many university-qualified educators in the Australian context, due to the high demand for educators with these qualifications to meet the government's commitment to universal access to preschool for all four-year-olds in their year before school (Productivity Commission 2014). 
draws on Lara's experiences of her work environments, along with existing research on educators' experiences of work environments, the Australian policy context, and concepts drawing on Deleuze and Guattari's work, to generate new possibilities for thinking about workforce stability and sustainability.

\section{Readings}

In this part of the article, readings are given to illuminate the questions - how do macroand micropolitics operate between Lara and her work environment? and, what do the exchanges of these politics produce? There are two parts to the readings. The first part deals with Lara's experiences of the exchanges of macro- and micropolitical flows on entering her work environment. The second part of the readings deals with the effects produced through the exchanges of macro- and micropolitics that seemed to constrain Lara's capacity to manifest her preferred way of being an educator.

The readings draw upon visual, textual and affective data generated through the research study. Figure 1 presents the visual collage that Lara made as part of the research study (for readability, I have enlarged the written material in the images and added it alongside Lara's collage). Figures 2 and 3 were created by me as part of the analytic process. These figures include comments made by Lara in the focus group discussions, and our individual research conversation (identified by reading intensively). Lines have also been added to give a sense of the forces (and effects) that Lara seemed to be conveying.

As the graduation image at the top right of Lara's collage illustrates, she completed her degree studies with a sense of freshness and excitement. However, entering the work environment produced a number of unexpected effects for Lara. The first of these effects were visceral impacts produced through the meeting of Lara's way of being an educator (wanting change and difference) and her colleagues (perceived) "set" state of being. Lara conveyed these impacts through her description "BANG", and of having her creativity "cut off". Similarly, the gesture and sound effect of a car zooming away (in the quote on the right hand side of Figure 2) indicate her sense of something valued speeding away from her. The visceral quality of these experiences conveys the intensity of the impact for Lara of entering her first early childhood education work environment.

The second unexpected effect for Lara concerned her perceptions of differences between the seemingly 'set' ways of being amongst her colleagues in their work environment and her desire for change. For example, her quote (in Figure 2): "we work as we are. We don't really need change"conveys a sense of the stabilising (or, macropolitical) force in her work environment. Viewing the image of the circle of figures, and listening to Lara's explanation that she had "just Googled exclusion" to locate it suggested to me that Lara had experienced a sense of ostracism. However, she went on clarify that 'exclusion' did not quite convey her experiences, saying: "I think it's more than exclusion but...it's less of being excluded and more that they don't want to change". Trying to gain a sense of her experience, I asked Lara: "what would make it possible for you to join the circle?" and she answered: 
I don't want to join the circle because they're all doing the exact same thing. They don't want to change. I want all of them to get some colour and not be closed off. I see it as a group of people blocking the way for change - facing out. (fragment from research conversation)

The difference that Lara perceived (and seemed to desire) was what Deleuze described as "difference in itself", or, "the particularity or 'singularity' of each individual thing, moment, perception or conception" (Stagoll, 2010, p. 74). That is, Lara was not defining her way of being as 'different from' the others, nor was it her perception that they were excluding her. Rather, her desired way of being an educator was to have the capacity to move and to change, or, to work in micropolitical ways.

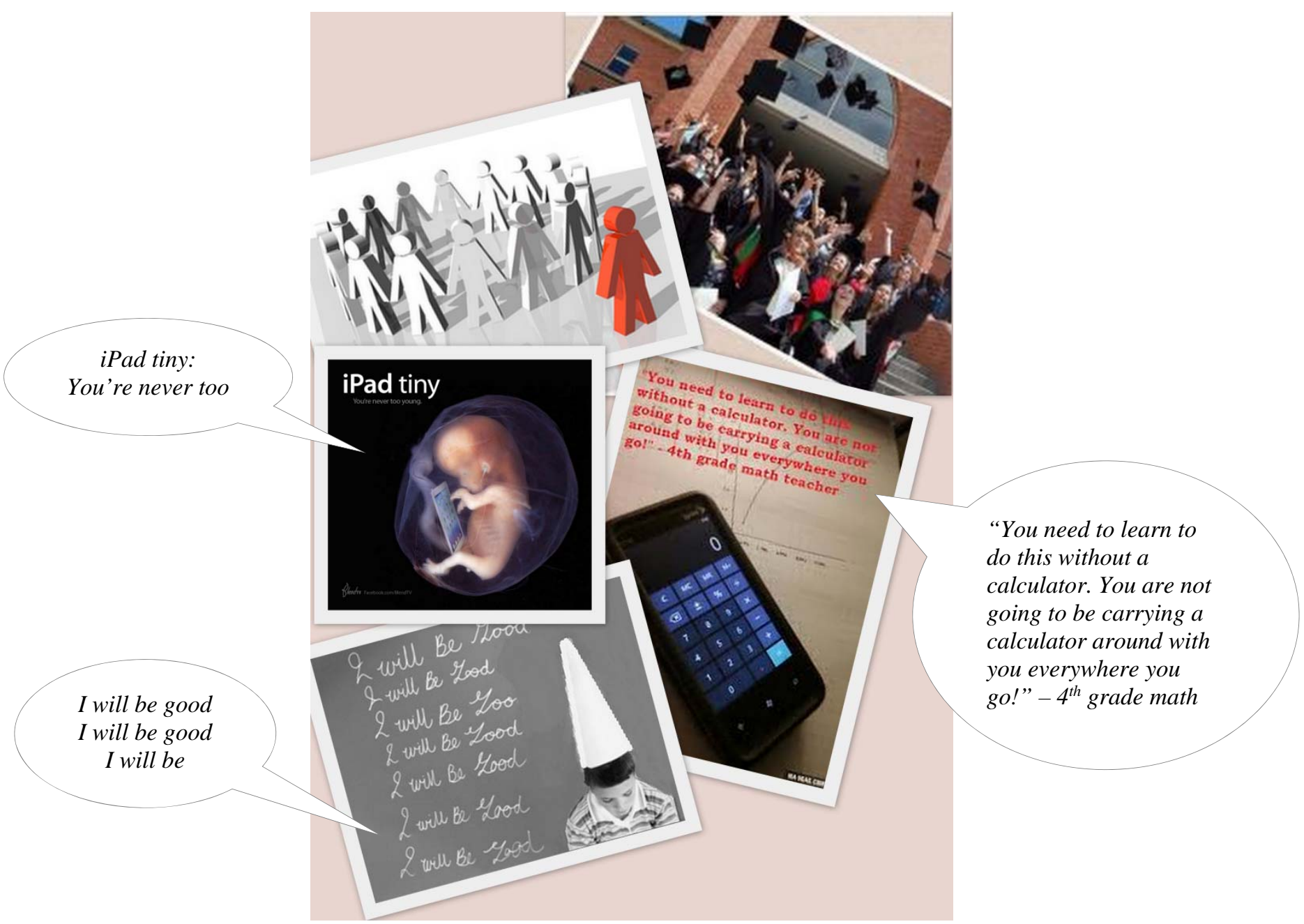

Figure 1. Lara’s visual collage

\section{Unexpected (and) constraining effects}

Despite this apparent desire for 'difference', over time, exchanges of macro- and micropolitical flows between herself and her colleagues had a third unexpected and constraining effect for Lara: 
Facilitator 4 . ...if you are challenged and there are consequences, how do you feel ...if you aren't comfortable with them?

Lara: Really constricted...because you can't do what you think you should be doing, so you're kind of always watching what you're doing, if that makes sense?

F: And how do you - what sort of emotion - you're saying constricted, you're saying frustrated, but, how do you actually feel about that?

L: I don't know. You get boxed in... You feel like you can't do the changes that you want and you have other changes forced on you that you don't want. (fragment from initial focus group discussion)

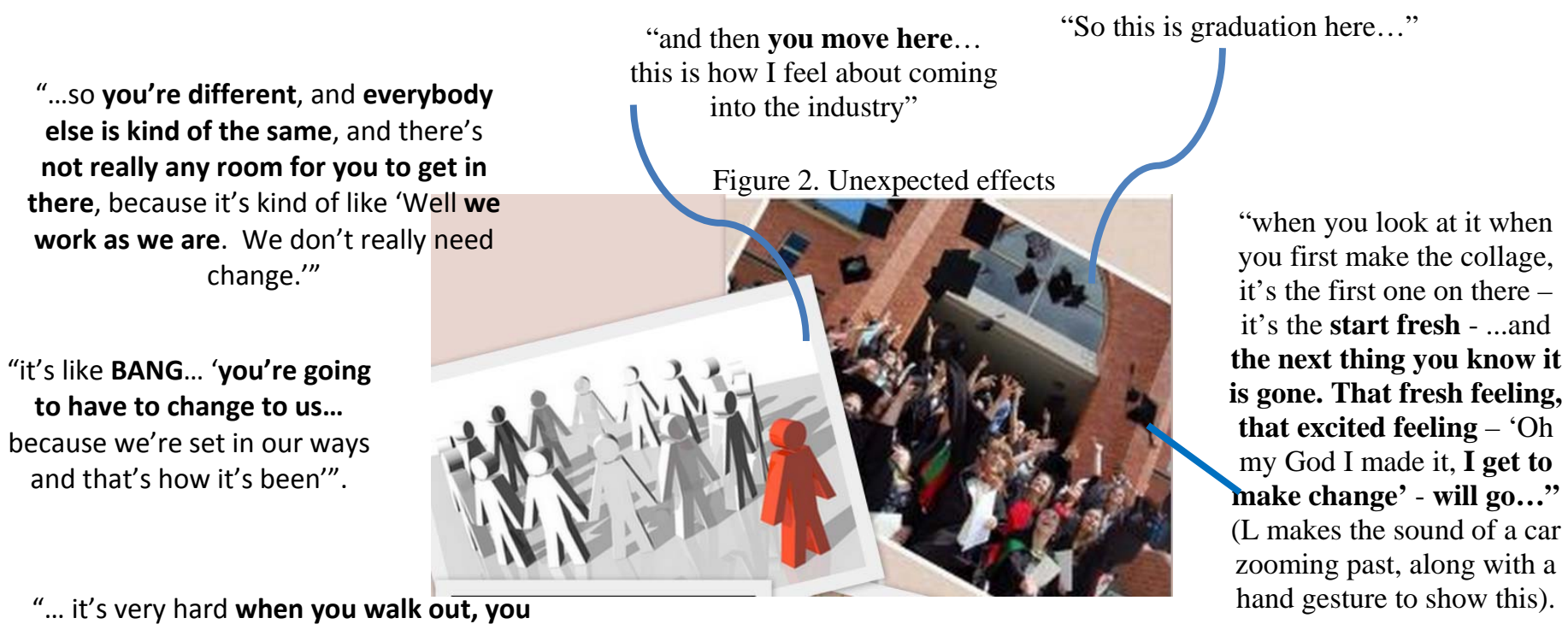

"... it's very hard when you walk out, you

walk in somewhere and they go 'No you

can't do those changes, this is how we're

doing it and you can't do that' and you're

like, 'oh my creativity that I just spent 4

years developing just got cut off!'

Lara's sense of being "constricted", "boxed in", and of having "changes forced on [her]" that she did not want, convey her sense of frustration and constraint. The exchanges of macro- and micropolitical flows within Lara's work environment also produced a sense of compulsion to modulated her own behaviour via self-surveillance - "always watching what you're doing" - to fit in with others' preferred ways of doing and being. In this way, it seemed that Lara had been forced to exchange her preferred way of operating in micropolitical ways for enacting the regulating and stabilising forces of 'the same'.

${ }^{4}$ An expert focus group facilitator was used to guide the discussion for the first of the two initial focus group discussions. As a result of this guidance and mentoring, the author took on more of the main group facilitation in subsequent group discussions. 


\section{1. (Im)possible ways of being an educator?}

As the forces of 'the same' in her work environment continued to collide with her desire for change, Lara's capacity for manifesting her preferred ways of being an educator seemed to be diminishing. Two of Lara's comments about the circle image overlapping the graduation image (see Figure 3) illustrate this point: “...it's gotten to the point [that] it's already soiled. I don't think you can peel this [the circle image] off it [the graduation image] now", and, "can you stop that there [the overlapping]? Because if it goes any further, I'm gone".

With these comments in mind, in the follow-up focus group (conducted about a month after our interview), I asked Lara to think again about her experiences:

“...it's gotten to the point, like I don't know if you can ...it's already soiled.

I don't think you can peel this [the circle image] off it now."

Lara makes a hand gesture as if peeling back the circle image from the graduation image.

"...technology is the main thing that's changing. I know regulations and all that have all changed, but the main thing that changes in our generation and will change in

the next generation is technology - technological advances"

Q: Some of these images are over the top of each other... "I was trying not to block out things but I wanted to show technology [at] the front, and this one just behind it, because [even though] this is an outdated sense of punishment that has been phased out, children still get made to write lines at school...the fact that that still goes on - it's because they're not willing to change they're not willing to try."

\section{Q: See how the graduation \\ photo is tucked underneath? Do} you feel like that's
disappearing? you feel like that's
disappearing? you feel like that's
disappearing? 
T: ...Lara I think that was your term - feeling constricted and boxed in by what choices might be available in a setting. Does anything else come to mind with that?

Lara: I just, I think that a lot of the movement, it all comes back to being constricted because you may bend but then something will just bring you straight back. So it's a lot of "I'll try this, I'll try this, I'll try this" and then, in the end it's like "Why try it?

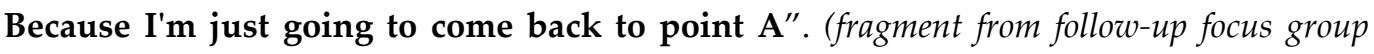
discussion)

Although there was a sense of movement in Lara's account - an elastic stretching-out, or bending-towards as she tried things out - "I'll try this, I'll try this, I'll try this"... she perceived that her attempts to do things differently - to be different/ly - were ultimately shut down by the constant repetition of movements assembling her into the same. At this point, the effects of the macropolitical forces in Lara's work environment seemed unavoidable. However, just as Deleuze and Guattari contend, it is micropolitics that "makes it or breaks it" (1987, p. 244), Lara retained a sense of other possibilities with which it seemed she could move on. This was evident as she referred to the lower part of her collage (see Figure 3), for example, indicating that although "that part's gone" (her feelings on completing her degree), she could "still make this part good" (the lower part of the collage).

The three images in the lower part of Lara's collage juxtapose elements of the embryonic, futuristic and anachronistic. Lara had placed the images of the iPad tiny and calculator to overlap the image of the circle - just as the iPad tiny was placed to encroach on the dunce cap image. As she pointed out, "things like this [the dunce cap image] they may work but that doesn't mean that it's not going to change". Lara saw technology, and willingness to embrace the possibilities offered by technology, as the main drivers for change in her generation of educators, and for the next. In this way, the lower part of the collage - and its futuristic focus - appeared to be a space through which Lara anticipated that she could reactivate her micropolitical capacity for producing preferred ways of being an educator.

\section{Possibilities}

As Olsson (2009, p. 27) suggests: "When the conditions for thinking are changed..., there are possibilities to think, speak and live in ways that are not already known". In the same way, the use of concepts of macro- and micropolitics to read Lara's experiences has enabled a variety of "previously unthought" (Mazzei \& McCoy, 2010, p. 504) possibilities. Firstly, thinking about "ideas, fragments, theory, selves, sensations" (Jackson \& Mazzei, 2013, p. 262) via the readings of visual, affective and textual data, has enabled readings of being, and the shaping of being, that might not otherwise have become possible. "In particular, these readings have enabled conceptualisations of ways educators' subjectivities are shaped that are not reliant on dominant humanist conceptualisations of educators as autonomous, and independent from the environment in which they act" (Cumming \& Sumsion, 2014). Rather, Lara's entanglement in the exchanges of macro- and micropolitics of her work environment, her meldings of 
images, words, senses, technology, gestures, relationships, past, present, and hopes for the future, convey some of the complex interrelations of elements implicated in shaping an educator's subjectivity.

The readings of the effects for Lara of her entanglements in macro- and micropolitical exchanges also contribute to existing literature concerned with effects of work environments on other educators. For example, the readings confirm observations of factors such as cultures and stress in work environments having significant impacts on educators (The Social Research Centre, 2014). In addition, the readings echo some conclusions made by Gable et al. (2007) and Cassidy et al. (2011). Lara's experiences resonated for example, with conclusions drawn regarding the difficulties for universityqualified educators of feeling professionally isolated (Gable et al., 2007). Similarly to Cassidy et al. (2011), the readings of Lara's experiences also made visible some of the effects that can be produced from the complex interrelatedness of factors in work environments. These effects included Lara's experiences of the visceral impacts of microand macropolitical forces colliding as she entered her work environment as a beginning educator. These experiences resonate with literature documenting other educators' disillusionments as they began practice (Noble and MacFarlane's, 2005; Sumsion, 2004), and with the forms of 'violence' discussed by Hard (2006) and Sumsion (2001).

At the same time, taking a theoretically and conceptually innovative approach (such as Sumsion, 2007, advocates) has generated new insights regarding the complexity of educators' experiences in work environments. For example, the readings suggest that along with the 'discursive landscapes' identified by Osgood (2006), exchanges of macroand micropolitical forces seem to be implicated in shaping (un)acceptable ways of practicing, or of being an educator. The readings of Lara's experiences also add another dimension to discussions of what might support educators' resilience (Sumsion, 2004) suggesting that a mismatch of educators' orientations to change can be damaging to their resilience and thriving. Indeed, Lara's sense of being forced to exchange her preferred (micropolitical) way of way operating for her colleagues' stabilising (macropolitical) way, suggests the way that exchanges in educators' work environments can severely constrain their capacity for manifesting change.

It seems then, that making space for multiple ways of being an educator could offer opportunities for the kind of "vital, intense and unpredictable experimentation" (Olsson, 2010, p. 6) that might be both highly generative for children, and, satisfying for educators. Accordingly, conditions within work environments (such as highlighted by Kusma et al. 2012; and Fenech et al., 2010), as well as those of policy, educational and regulatory environments (ILO, 2014), need to align with a goal of supporting workforce stability and sustainability. An implication of these readings then, is the need for recognition of the value of making (and keeping) opportunities open for practices of possibilities (such as Lara seemed to desire). In relation to work environments for example, recognising ways macropolitical forces may be constraining possibilities, or ways that educators successfully negotiate change might support efforts to keep space open for these practices. 
In relation to approaches to policy making, conditions of possibility could include “...spaces for political action that recognise and generate localised responses, whilst at the same time engendering policy that enables more broadly based social justice" (Press and Skattebol, 2007, p.180). In addition, funding commitments to support these goals must be sustained across time (Brennan and Adamson, 2014). This proposition has particular resonance for the Australian context, where, as of 2015, subsidies of fees for (some) educators' degree or vocational education courses, introduced by the previous federal government as part of the Early Years Workforce Strategy (SCSEEC, 2012) will be discontinued (DE, 2014). In addition, it seems possible that ideological differences between Australia's major political parties regarding the purpose of early childhood education (as EITHER a mechanism to support women's workforce participation OR the right of all children) may create new fragmentations (Institute of Early Childhood, 2014).

\section{Closing thoughts}

In this article using the concepts of macro- and micropolitics has helped make visible some of the complex exchanges between an educator and her work environment, and the constraining and enabling effects of these exchanges. The readings of Lara's experiences also gesture to the need for conditions of possibility to be fostered in work environments, both in terms of educators' practice, and their capacity to shape productive ways of being. By making and keeping these spaces open, educators' resilience and capacity for enabling change might be better supported.

At the same time as conditions of possibility need to be enabled in work environments, sustained government attention and action is also needed. In particular, action concerning the remuneration and conditions commensurate with the skills, knowledge and value of early childhood educators is needed to sustain their capacity to remain in the sector. Additionally, policy, educational and regulatory environments (ILO, 2014) need to be orientated to creating and maintaining conditions that support workforce stability and sustainability. By creating the conditions in which educators thrive, conditions will be enabled for families, the economy, and for children to thrive.

\section{References}

Australian Government Department of Education. (2014). Early Childhood Workforce Initiatives. Retrieved from http://education.gov.au/early-childhood-workforce-initiatives

Brennan, D. \& Adamson, E. (2014). Financing the future: An equitable and sustainable approach to early childhood education and care. Sydney, Australia: Social Policy Research Centre. https://www.sprc.unsw.edu.au/media/SPRCFile/Financing the Future.pdf

Cassidy, D.J., Lower, J.K., Kintner-Duffy, V.L., Hegde, A.V., \& Shim, J. (2011). The day-to-day reality of teacher turnover in preschool classrooms: An analysis of classroom context and teacher, director, and parent perspectives. Journal of Research in Childhood Education, 25(1), 1-23. doi:10.1080/02568543.2011.533118

Cumming, T. (2014). Challenges of 'thinking differently' with rhizoanalytic approaches: A reflexive account. International Journal of Research \& Method in Education, 38(2), 137-148. doi:10.10/1743727X.2014.896892 
Cumming, T. \& Sumsion, J. (2014). A politics of imperceptibilities, possibilities and early childhood practice. Contemporary Issues in Early Childhood, 14(4), 368-377. doi:10.2304/ciec.2014.15.4.368

Cumming, T., Sumsion, J., \& Wong, S. (2015). Rethinking early childhood workforce sustainability in the context of Australia's early childhood education and care reforms. International Journal of Child Care and Education Policy.

Deleuze, G. (1995). Negotiations 1972-1990 (M. Joughin, Trans.). New York: Columbia University Press.

Deleuze, G. \& Guattari, F. (1987). ATthousand plateaus: Capitalism and schizophrenia (B.Massumi, Trans.). London: Continuum.

Fenech, M., Sumsion, J. \& Shepherd, W. (2010). Promoting early childhood teacher professionalism in the Australian context: The place of resistance. Contemporary Issues in Early Childhood, 11(1), 89-105. doi: 10.2304/ciec.2010.11.1.89

Giugni, M. (2011). 'Becoming worldly with': An encounter with the Early Years Learning Framework. Contemporary Issues in Early Childhood, 12(1), 11-27. doi:10.2304/ciec.2011.12.1.11

Hard, L. (2006). Horizontal violence in early childhood education and care: Implications for leadership enactment. Australian Journal of Early Childhood, 31(3), 40-48.

Institute of Early Childhood. (2014). Comment on the Productivity Commission's Childcare and Early Childhood Learning Draft Report. Sydney, Australia. http://pc.gov.au/ data/assets/pdf file/0006/143538/subdr700-childcare.pdf

International Labour Organization. (2014). ILO Policy Guidelines on the promotion of decent work for early childhood education personnel. Geneva. http://www.ilo.org/sector/Resources/codes-ofpractice-and-guidelines/WCMS 236528/lang--en/index.htm

Jackson, A.Y., \& Mazzei, L.A. (2013). Plugging one text into another: Thinking with theory in qualitative research. Qualitative Inquiry, 19(4), 261-271. doi:10.1177/1077800412471510

Kim, M. (2004). Teachers' philosophical orientation and practices: a study of novice preschool teachers in South Korea. Contemporary Issues in Early Childhood, 5(3), 276-292.

Kusma, B., Groneberg, D.A., Nienhaus, A. \& Mache, S. (2012). Determinants of day care teachers' job satisfaction. Central European Journal of Public Health, 20(3), 191-198.

Livesey, G. (2010). Assemblage. In A. Parr (Ed.), The Deleuze Dictionary (Rev. ed.) pp. 18-19. Edinburgh: Edinburgh University Press.

May, T. (2005). Gilles Deleuze: An introduction. Cambridge, UK: Cambridge University Press.

Mazzei, L.A., \& McCoy, K. (2010). Thinking with Deleuze in qualitative research. International Journal of Qualitative Studies in Education, 23(5), 503-509. doi:10.1080/09518398.2010.500634

Noble, K. \& Macfarlane, K. (2005). Romance or reality?: Examining burnout in early childhood teachers. Australian Journal of Early Childhood, 30(3), 53-58.

Olsson, L.M. (2009). Movement and experimentation in young children's learning: Deleuze and Guattari in early childhood education. Abingdon, UK: Routledge.

Organisation for Economic Co-operation and Development. (2012). Starting Strong III: A quality toolbox for early childhood education and care: OECD Publishing. http://dx.doi.org/10.1787/9789264123564-en

Osgood, J. (2010). Reconstructing professionalism in ECEC: the case for the 'critically reflective emotional professional'. Early Years: An International Research Journal, 3(2), 119-133. doi:10.1080/09575146.2010.490905

Pacini-Ketchabaw, V. (2013). Politicizing transitions in early childhood. Global Studies of Childhood, 3(3), 221-229. doi:10.2304/gsch.2013.3.3.221

Press, F. \& Skattebol, J. (2007). Early childhood activism, minor politics and resuscitating vision: a tentative foray into the use of 'intersections' to influence early childhood policy. Contemporary Issues in Early Childhood, 8(3), 180-191.

Productivity Commission. (2014). Childcare and early childhood learning, Draft Report. Canberra. http://www.pc.gov.au/_data/assets/pdf_file/0008/138383/childcare-draft.pdfStagoll, C. (2010). 
Difference. In Adrian Parr (Ed.), The Deleuze Dictionary (Revised ed., pp. 74-76). Edinburgh: Edinburgh University Press.

Sumsion, J. (2001). Workplace violence in early childhood settings: A counter-narrative. Contemporary Issues in Early Childhood, 2(2), 195-208.

Sumsion, J. (2004). Early childhood teachers' constructions of their resilience and thriving: a continuing investigation. International Journal of Early Years Education, 12(3), 275-290. doi:10.1080/096697604200026873.

Sumsion, J. (2007). Sustaining the employment of early childhood teachers in long day care: A case for robust hope, critical imagination and critical action. Asia-Pacific Journal of Teacher Education, 35(3), 311-327.

The Social Research Centre. (2014). 2013 National Early Childhood Education and Care Workforce Census. Melbourne, Australia: Department of Education. http://docs.education.gov.au/system/files/doc/other/nwc national report final.pdf

Whitebook, M. \& Ryan, S. (2011). Degrees in context: Asking the right questions about preparing skilled and effective teachers of young children. New Jersey, US: National Institute for Early Education Research.

\title{
Acknowledgements
}

I would like to acknowledge and thank 'Lara', whose courage and capacity for being difference-initself continues to inspire me. I also gratefully acknowledge and thank the anonymous reviewers of this article, along with Prof. Jennifer Sumsion and Dr Sandie Wong, for their insightful, critical feedback.

\begin{abstract}
About the Author
Tamara Cumming is a researcher and lecturer in early childhood studies at Charles Sturt University, Australia. Tamara's research interests focus on the early childhood workforce. Her recently completed doctoral thesis was concerned with making visible the complexity of early childhood practice, and educators' ways of negotiating this complexity. Her other interests include poststrutural theory, interprofessional work, and workforce sustainability. Tamara can be contacted at tcumming@csu.edu.au.

(C) Copyright 2015. The author, TAMARA CUMMING, assigns to the University of Alberta and other educational and non-profit institutions a non-exclusive license to use this document for personal use and in courses of instruction provided that the article is used in full and this copyright statement is reproduced. The author also grants a non-exclusive license to the University of Alberta to publish this document in full on the World Wide Web, and for the document to be published on mirrors on the World Wide Web. Any other usage is prohibited without the express permission of the authors.
\end{abstract}


